\title{
Balkanologie
}

Balkanologie Revue d'études pluridisciplinaires

Vol. XII, $n^{\circ} 2$ | 2010

Volume XII Numéro 2

\section{Le printemps croate dans la presse quotidienne française}

Ines Sabotič

\section{OpenEdition}

Journals

Édition électronique

URL : https://journals.openedition.org/balkanologie/2251

DOI : 10.4000/balkanologie.2251

ISSN : 1965-0582

Éditeur

Association française d'études sur les Balkans (Afebalk)

Référence électronique

Ines Sabotič, «Le printemps croate dans la presse quotidienne française », Balkanologie [En ligne], Vol. XII, $n^{\circ} 2$ | 2010, mis en ligne le 07 février 2013, consulté le 28 juin 2022. URL : http://

journals.openedition.org/balkanologie/2251; DOI : https://doi.org/10.4000/balkanologie.2251

Ce document a été généré automatiquement le 17 décembre 2020.

(c) Tous droits réservés 


\title{
Le printemps croate dans la presse quotidienne française
}

\author{
Ines Sabotič
}

\section{Introduction}

1 «Grève des étudiants de l'Université de Zagreb " (L’Humanité, 24 novembre 1971), «A Zagreb, les étudiants ont manifesté en faveur des dirigeants démissionnaires » (Le Monde, 15 décembre 1971), « 234 arrestations à Zagreb » (Le Figaro, 17 décembre 1971), "Tito sanctionne les nationalistes croates" (Le Figaro, 13 décembre 1971), ... Ces quelques titres issus des principaux quotidiens français se font l'écho des événements qui ont, durant l'hiver 1971-1972, secoué la République socialiste de Croatie et, par là même, la République fédérale socialiste de Yougoslavie. Ces événements ont révélé des relations tendues et difficiles entre, d'une part, les Croates réclamant une plus grande liberté et, d'autre part, le parti communiste yougoslave opposé à la lui donner. De ce fait, ils ont trouvé leur place dans la presse internationale ${ }^{1}$, mais ils sont surtout devenus un lieu de mémoire, un épisode fondateur de l'histoire croate contemporaine. D'ailleurs, ce mouvement a rapidement été surnommé le Printemps croate, par analogie au Printemps de Prague de 1968, symbole du combat pour la liberté, un combat étouffé par un pouvoir sans merci. Cette expression n'a pas été utilisée par les journalistes français lors des événements ${ }^{2}$; à l'opposé, l'expression MASPOK (masovni pokret - mouvement de masse), utilisée par ses détracteurs - les autorités communistes - l'a été à peine plus ${ }^{3}$.

2 Avant de nous pencher plus amplement sur les articles des journaux français ${ }^{4}$, il convient de rappeler quelques moments clés qui ont précédé le Printemps croate ${ }^{5}$. La « Déclaration sur l'appellation et la position de la langue littéraire croate » (Deklaracija o nazivu i položaju hrvatskog književnog jezika), rédigée et signée par les intellectuels croates en 1967, est une première étape importante. Elle remet en cause l'Accord de Novi Sad (1954), qui promouvait le serbo-croate, et affirme l'existence d'une langue croate. Cette Déclaration eut un grand retentissement dans l'opinion publique croate, 
particulièrement sensibilisée alors à la question nationale. Cette question prit également une dimension politique dans la mesure où certains débats sur des changements constitutionnels étaient engagés. En janvier 1970, au X ${ }^{\text {ème }}$ Plénum du Comité central de la Ligue des communistes de Croatie, les dirigeants croates, Savka Dabčević-Kučar, présidente du Comité central de la Ligue des communistes de Croatie, Pero Pirker, son secrétaire, et Miko Tripalo, membre de la présidence de la RSFY, ont soutenu les revendications croates, ce qui les a rendus particulièrement populaires. L'institution culturelle Matica Hrvatska joua également un rôle important, notamment sur la scène culturelle et intellectuelle. Grâce à son journal Hrvatski tjednik - novine za kulturna $i$ društvena pitanja (L'hebdomadaire croate - journal pour les questions culturelles et sociales), ayant pout rédacteur en chef Igor Zidić, puis Vlado Gotovac, l'institution était devenue le porte-parole du mouvement. Les étudiants, enfin, avec Ivan Zvonimir Čičak, vice-recteur depuis novembre 1970, et Dražen Budiša, élu président de la Ligue des étudiants de Zagreb en avril 1971, ont également activement participé à ce mouvement. Ils étaient davantage dans l'action, à l'initiative d'une grève qui a d'ailleurs été le point culminant du mouvement et l'épisode le plus contestataire. Cette phase aiguë a duré une dizaine de jours, jusqu'à la XXI ${ }^{\text {ème }}$ session du Présidium de la Ligue des communistes yougoslaves, le $1^{\mathrm{er}}$ décembre 1971 à Karađorđevo.

3 Au-delà de l'hétérogénéité des protagonistes (pas nécessairement homogènes au sein même de leur groupe d'ailleurs), utilisant des méthodes diverses et agissant dans des domaines différents (du discours à l'acte politique), tous réclament au moins la décentralisation et la libéralisation dans plusieurs domaines : la culture (utilisation du croate), la politique (changements institutionnels) et l'économie (question des devises). La volonté de réformer la fédération yougoslave, plus précisément d'accorder une plus grande autonomie aux républiques et d'assurer une plus grande égalité entre elles, est clairement exprimée. L'exigence d'une confédération yougoslave ou même d'une indépendance de la Croatie ont également été mentionnées.

Depuis plusieurs mois déjà, Josip Broz Tito, président de la Yougoslavie, était particulièrement attentif aux revendications croates. En juillet 1971, il avait déjà rencontré les dirigeants croates afin de les mettre en garde contre le nationalisme et le séparatisme grandissant. La sévérité de cet avertissement a été rapidement suivie de l'exclusion de Šime Đodan et de Marko Veselica de la Ligue des communistes de Croatie en raison de leurs engagements au sein de la Matica Hrvatska. En octobre, l'Armée populaire yougoslave faisait des exercices militaires montrant qu'elle était prête, en cas de nécessité, à faire face à toutes les situations. Au niveau international, le pouvoir central faisait également preuve de vigilance et de contrôle. Tito avait effectivement rencontré Richard Nixon et Leonid Brejnev en automne. Néanmoins, quelques mois plus tard, à Karađorđevo, la crise allant grandissant, les autorités ont décidé d'y mettre un terme. Peu de temps après, les leaders des étudiants et de la Matica Hrvatska ont été arrêtés et condamnés à des peines de prisons, les dirigeants croates limogés, le parti communiste croate purgé, la presse muselée.

5 Contrairement à la période communiste, qui condamna le Printemps croate, la période inaugurée en 1990 par l'acte d'indépendance la magnifia. Avoir participé aux événements de 1971, et surtout avoir fait de la prison à cause de cet engagement, donnaient aux hommes politiques et aux intellectuels un gage de légitimité, une preuve de leur anti-communisme et de leur combat pour la démocratie et l'indépendance ${ }^{6}$. Néanmoins, des débats et des polémiques se posent aujourd'hui encore sur le rôle des 
divers protagonistes, sur la nature des objectifs politiques et des aspirations du mouvement croate (vers une indépendance de la Croatie ou une réforme de la Yougoslavie !). Cet épisode, dont certains des principaux protagonistes sont encore en vie, fera certainement encore l'objet de nombreux travaux et de nouvelles recherches afin d'éclairer cette page importante de l'histoire croate.

Les articles des quotidiens français portant sur le Printemps croate posent la question du regard des journalistes sur cet événement et de leurs interprétations des faits. Le but de cet article n'est donc pas de proposer une vision du Printemps croate selon la perspective croate ou yougoslave, mais selon la perspective des journalistes français, exemple d'un regard de l'étranger. Un regard de l'extérieur est sans aucun doute différent de celui de l'intérieur puisque les informations, les engagements, les positions, les enjeux eux-mêmes le sont.

Pour mener à bien ce but, il a été nécessaire de faire une analyse des articles de journaux des trois principaux quotidiens français, Le Monde, Le Figaro et L'Humanité, publiés pendant les deux mois clés du Printemps croate, en l'occurrence du 24 novembre 1971 au 28 janvier 1972. On compte en tout 61 articles (un par journal et par jour, très rarement deux) parus en général dans la rubrique des affaires internationales. Près de la moitié des articles est sortie dans Le Monde (31), tandis que les deux autres journaux y ont consacré deux fois moins de place : Le Figaro a publié 16 articles, L'Humanité 14 . Seul Le Monde a, à deux reprises, mis le sujet en première page. Les articles sont de nature différente, il y a des articles informatifs issus d'agences de presse (39), des articles analytiques (14), et enfin des reportages et commentaires (7). Afin de tirer profit de ces textes, deux types d'analyse ont été faits, le premier qualitatif, le second quantitatif.

De quelle manière les journaux français ont-ils écrit sur le Printemps croate! Sur quoi ont-ils mis l'accent! Qu'ont-ils dissimulé ! Quels acteurs ont été mis au premier plan, au second plan! Qui sont les journalistes! Afin de répondre à ces nombreuses questions, il convient de se pencher d'abord sur la chronologie du Printemps croate à travers ces articles de journaux, puis de faire une analyse de leur contenu, et finalement de terminer par un tableau des regards que les journalistes ont posés sur ce mouvement, et plus généralement sur la Yougoslavie.

\section{Une chronologie du Printemps croate}

9 Afin que l'analyse quantitative ne dépouille pas la réalité du Printemps croate, il est nécessaire de revenir aux faits d'actualité présentés dans la presse et de reconstruire la chronologie de cette crise. Ici, on s'intéresse surtout aux articles informatifs (brèves et dépêches issues d'agences de presse, à savoir des textes plutôt courts communiquant des informations élémentaires sur un événement) et aux articles analytiques (informatifs mais plus longs et analytiques que les précédents, en général écrits par les correspondants) qui relatent les faits. Les titres de ces articles (quand il y en a) ont particulièrement été pris en compte dans la mesure où ce sont les éléments les plus lus des journaux. On dispose donc de 53 articles (reportages et commentaires exclus), soit 44 titres. Cette chronologie qui repose sur une analyse des articles est une forme d'analyse qualitative étant donné que l'événement peut aussi être présenté de manière différente et être sujet à interprétations diverses. 


\section{a) La grève des étudiants}

10 Dès le 24 novembre 1971, les trois quotidiens rapportent la grève des étudiants de Zagreb qui avait commencé le jour précédent. Paul Yankovitch du Monde en a fait l'exposé le plus complet. Dans son article intitulé "Yougoslavie. Les étudiants de Zagreb veulent obliger la "bureaucratie fédérale" à accepter les revendications de la Croatie", il insiste sur les revendications croates qui sont de nature politique et économique. Il mentionne Ivan Zvonimir Čičak, vice-recteur étudiant, qui appelle les ouvriers à se joindre au mouvement contre «le "pillage" de l'économie croate ", à savoir contre la politique des devises mise en place par Belgrade, défavorable à la Croatie selon les Croates. Pour le journaliste, ce problème a pris une nouvelle dimension suite aux changements constitutionnels du 31 juillet 1971. Ces mêmes changements ont en effet attisé d'autres revendications, à savoir «l'admission de la Croatie aux Nations-Unies, puis la formation d'une armée nationale croate ». L'Humanité et Le Figaro n'ont en revanche mentionné aucune des revendications politiques des étudiants. Les quotidiens n'ont effectivement pas mentionné les Conclusions du groupe des étudiants du 22 novembre 1971 qui exposaient clairement leurs positions et exigences (comme par exemple faire le service militaire en Croatie et non pas dans une autre république).Enfin, Yankovitch, dans son article, cite la réaction de Nikola Ljubičić, général de l'Armée populaire yougoslave et ministre de la Défense, qui demande à l'armée de faire preuve d'une "entière vigilance ». Environ une semaine après le début de la grève, le 3 décembre 1971, tous les journaux en ont signalé la fin. Le Figaro titre "Avertissement du président Tito aux dirigeants croates » et fait part des principales réactions des autorités yougoslaves face aux événements croates. On peut remarquer que le journaliste ne précise pas que cet avertissement a été fait en Serbie, à Karađorđevo, où des réunions politiques essentielles ont pourtant été organisées : la rencontre entre Tito et le Comité exécutif de la Ligue des communistes de Croatie (30 novembre $-1^{\text {er }}$ décembre 1971) et la XXI ${ }^{\text {ème }}$ session du Présidium de la Ligue des communistes de Yougoslavie ( $1^{\text {er }}$ et 2 décembre 1971). On observe les premiers échos dans la presse française de cet événement politique le 4 décembre seulement dans un article de Yankovitch du Monde. Le journaliste n'évoque plus la grève des étudiants, son attention porte avant tout sur les dirigeants croates et la Matica Hrvatska qui ont été sévèrement condamnés pour "nationalisme » et "contre-révolution ». Il mentionne également le "groupe des cinquante », mais sans définir cette expression utilisée par le parti pour désigner les principaux « contre-révolutionnaires ». Une place particulière a été faite à Tito qui a d'ailleurs fait le titre de l'article : «Après la grève des étudiants de Zagreb. Le maréchal Tito reproche aux dirigeants croates d'avoir fait preuve de "libéralisme pourri" " et dénonce "un nouveau mouvement national» (Le Monde, 4 décembre 1971). On remarque que l'axe du problème se déplace, on passe des étudiants aux dirigeants politiques et à la Matica Hrvatska, la nature des événements prend une dimension nationale et plus grave.

Une semaine plus tard, Le Monde publie une dépêche d'agence (AFP) au titre suivant : «Un dirigeant croate dénonce l'existence d'une puissante organisation nationaliste au sein de la Ligue des communistes ». Le journaliste mentionne effectivement que le 7 décembre (dans l'article on ne mentionne que le mardi), Vladimir Bakarić a fait, à Virovitica, un discours dans lequel il a condamné le soutien des dirigeants croates au mouvement croate (Le Monde, 10 décembre 1971). On peut dire que c'est le début d'un règlement de compte politique qui a vu le jour à Karađorđevo. Paul Yankovitch publie, 
dès le lendemain, (Le Monde, 11 décembre 1971), un article intitulé « Après les critiques du maréchal Tito. Des organisations locales du parti demandent la destitution des principaux dirigeants croates » qui rend compte de la réunion des ouvriers de Sisak qui ont, le 9 décembre 1971, demandé la démission des dirigeants croates (voir aussi Le Figaro, 11 décembre 1971). Finalement, il apparaît que c'est la «base » qui initie une épuration du parti communiste croate, ce qui donne aux autorités la légitimité pour toutes les décisions et les mesures du moment, mais aussi ultérieures.

Des 53 articles retenus, seuls 11 ont été écrits avant le 12 décembre 1971, date à laquelle s'est tenu le XXIII ${ }^{\text {ème }}$ plénum du Comité central de la Ligue des communistes de Croatie (12-13 décembre 1971), nouvelle étape dans le dénouement de la crise. Les 10 titres (des 11 articles) reflètent les thèmes dominants de cette période : la grève des étudiants (mentionnée dans 5 des 10 titres) et les condamnations du parti (4 des 10 titres). Pourtant, après le 12 décembre 1971, le mot "crise »- qui révèle l'existence de problèmes plus profonds et sérieux - entre pour la première fois dans un titre ("Yougoslavie. La crise de Croatie rebondit », Le Figaro, 11 décembre 1971) et annonce une nouvelle phase dans la chronologie du Printemps croate.

\section{b) Vers le règlement de la crise : purges et arrestations}

En effet, cette réunion marque le début d'une réaction des autorités, non plus verbale, mais concrète, face aux principaux protagonistes. L'attention des journalistes français s'est déplacée vers des faits nouveaux : la démission des dirigeants croates ainsi que l'arrestation des étudiants et des membres de la Matica Hrvatska. Des 42 articles (en l'occurrence des 34 titres) publiés à partir du 13 décembre, 15 font référence à des mesures répressives (par exemple « Démission des 3 dirigeants croates ", L'Humanité, 13 décembre 1971 ; «234 arrestations à Zagreb", Le Figaro, 17 décembre 1971 ; " Démissions et destitutions de „nationalistes“", Le Monde, 26 décembre 1971) et 3 à des avertissements (par exemple "Croatie : le maréchal Tito brandit la menace d'un coup de "balai de fer" ", Le Figaro, 23 décembre 1971 ; «Tito : l'armée défendra les conquêtes de la révolution ", L'Humanité, 24 décembre 1971).

14 À la suite du XXIII ${ }^{2}$ e Plénum, Milka Planinc remplace Savka Dabčević-Kučar, Josip Vrhovec prend la place de Pero Pirker et Milan Mišković celle de Mika Tripalo. De courtes biographies sur les anciens et les nouveaux dirigeants ont alors été proposées aux lecteurs des trois journaux. Comme le signale L'Humanité du 13 décembre 1971, les raisons de ces démissions remontent à Karađorđevo. Surtout, elles ont été voulues par Tito, comme l'illustre le titre de la dépêche (AFP) dans Le Figaro "Tito sanctionne les nationalistes croates" (13 décembre 1971). Outre les démissions, Le Figaro fait également part des arrestations des représentants des étudiants, Dražen Budiša et Ivan Zvonimir Čičak, ainsi que des «manifestations», mais sans information supplémentaire. Le lendemain, L'Humanité signale « des désordres dans le centre de la ville ", sur la Place de la République (aujourd'hui Place du Ban Jelačić) qui ont été suivis par l'arrestation de 27 manifestants et de sévères avertissements de la police (L'Humanité, 14 décembre 1971). Le Figaro (14 décembre 1971) conclut, dans le titre même, que la situation est normalisée : «Le prestige de Tito renforcé par le dénouement de la "crise croate" ». Mira Traikovitch, l'auteur de cet article, considère en effet que la crise est terminée. 

étoffé sur ces derniers jours, riches en événements : sur le XXIII ème Plénum, les démissions et les nouveaux dirigeants croates, sur les manifestations des étudiants et leurs arrestations. Il écrit que « les autorités expliquent que ces étudiants ont essayé de "procéder au changement anticonstitutionnel et violent du régime social et politique" et au renversement du pouvoir établi. Ils avaient tenté, dimanche matin, de manifester en faveur des dirigeants critiqués, mais arrêtèrent leur mouvement après avoir appris les démissions ". La dernière constatation n'est pas complètement juste comme le montre, dès le lendemain, le titre de son article «Yougoslavie. À Zagreb des étudiants ont manifesté en faveur des dirigeants démissionnaires ». Surtout, Yankovitch note : «des heurts parfois violents se sont produits entre les manifestants et la police, casquée et armée de matraques. Il y a eu des blessés et soixante-seize arrestations ont été opérées. Les manifestants, en majorité des jeunes gens, ont scandé les noms de M. Tripalo, de Mme Kucar et des dirigeants étudiants arrêtés dimanche pour tentative de "changement constitutionnel et violation de l'ordre établi" " (Le Monde, 15 décembre 1971). Ces quelques lignes sont les seules qui témoignent du soutien des étudiants aux dirigeants démissionnaires et de la répression qui a suivi. Les jours suivants, ce sont les nouvelles arrestations des étudiants qui font l'actualité. Pourtant, cette information est assez sommaire. En effet, il est surtout question de chiffres, par exemple il y a eu 234 arrestations dans la cité universitaire "Nina Maraković» (Le Figaro, Le Monde, L'Humanité, 17 décembre 1971; Le Monde, 18 décembre 1971). Il a été accordé une place nettement moins importante aux arrestations des étudiants qu'à la nomination des nouveaux dirigeants. Par ailleurs, les journaux ont, à deux reprises, mis les paroles de Tito dans le titre de l'article, telle une explication aux mesures prises par les autorités pour mettre fin à la crise : "Tito: "Une extension de la crise en Croatie aurait pu entraîner l'intervention d'une armée étrangère" " (Le Figaro, 20 décembre 1971) et "Yougoslavie. Aurions-nous pu admettre que quelqu'un vienne rétablir l'ordre chez nous! déclare le maréchal Tito » (Le Monde, 21 décembre 1971). Le pouvoir communiste accuse tout particulièrement l'étranger, surtout «Moscou et ses amis » qui, selon lui, «encourageaient des mouvements d'extrême-droite qui dans l'émigration faisaient campagne pour l'indépendance de la Croatie ", mais aussi « flattaient les communistes “orthodoxes" chassés du pouvoir avec M. Rankovitch, et qui étaient imprégnés de "chauvinisme grand serbe" " (Le Monde, 24 décembre 1971).

Entre temps, la question des devises, au cœur même des revendications croates, a de nouveau été d'actualité, mais très brièvement. À la fin du mois de décembre, Paul Yankovitch publie un article au titre tout à fait évocateur : «Une concession aux Croates. Les Républiques yougoslaves modifient le système de répartition des devises " (Le Monde, 29 décembre 1971). Le Figaro ajoute que cette décision «favorise la Croatie, pays de tourisme » puisque les entreprises croates vont ainsi pouvoir garder $20 \%$ au lieu de $7 \%$ des devises gagnées, le secteur touristiques $45 \%$ au lieu de 12 \% (Le Figaro, 29 décembre 1971).

Au début de l'année suivante, en 1972, on écrit de nouveau sur les tensions en Croatie. Le 6 janvier, on apprend qu'un attentat a eu lieu à Zagreb, au siège du journal Borba et qu'il a coûté la vie à une personne (Le Monde et Le Figaro, 6 janvier 1972). Une semaine plus tard, L'Humanité (14 janvier 1972) et, un peu plus longuement, Le Monde (14 janvier 1972), font part de l'arrestation de onze membres de Matica Hrvatska. Paul Yankovitch écrit que les interpellations ont été faites «dans le cadre d'une violente lutte 
déclenchée par la nouvelle direction du parti croate conte les éléments "nationalistes, chauvins et séparatistes". Elle a déjà abouti à l'éviction de près de quatre-vingt-dix dirigeants». Les noms mentionnés sont Marko Veselica et Franjo Trudjnan (sic!), membres du Conseil d'administration de la Matica Hrvatska, Vlado Gotovac, rédacteur en chef de Hrvatski tjednik et Ante Glibota, secrétaire de la rédaction de Hrvatski gospodarski glasnik [Le Courier économique croate]. Le tribunal départemental de Zagreb les accuse d'avoir fondé « une organisation contre-révolutionnaire » avec pour objectif de « détruire par la force et d'autres moyens anticonstitutionnels le régime socialiste et l'organisation fédérative de la Yougoslavie », organisé la grève des étudiants qui aurait dû aboutir à la grève générale et collaboré avec « l'émigration fasciste oustachi » et les services de renseignements étrangers. Le journaliste informe aussi du début des " procès criminels ", mais ne mentionne pas les noms des personnes concernées.

Vers la fin du mois de janvier 1972, on assiste à la fin de cette crise. Le dernier événement qui a fait l'actualité est la Conférence de la Ligue des communistes de Yougoslavie sur laquelle Paul Yankovitch a fait trois articles relativement longs ( $L e$ Monde, 26, 27 et 29 janvier 1972). Leurs titres reflètent clairement la nouvelle direction que propose le parti : "Yougoslavie. La conférence de la Ligue des communistes s'efforce de réaffirmer l'unité du parti » (26 janvier 1972), «Yougoslavie. Le maréchal Tito affirme qu'il n'y a pas de crise de l'Etat » (27 janvier 1972) et "Yougoslavie. Pour mettre fin aux "déformations". La conférence de la Ligue des communistes décide un raidissement du régime » (29 janvier 1972). Mira Traikovitch du Figaro (28 janvier 1972) titre "Tito revalorise le principe du "centralisme démocratique" " et explique que l'autonomie des républiques va baisser au profit de la capitale fédérale, Belgrade.

\section{c) Epilogue}

Les autorités yougoslaves ont donc rapidement considéré les événements de Croatie comme une crise sérieuse qui pouvait mettre en danger la Yougoslavie car le séparatisme et le nationalisme, menaces essentielles pour le pouvoir, étaient à l'œuvre en Croatie. Les mesures et réactions du pouvoir étaient à la hauteur de cette menace. Néanmoins, dans les articles informatifs et analytiques, il n'y a pas d'explications ou d'informations supplémentaires sur ces affirmations. On s'est donc aussi penché sur les reportages et les commentaires. Outre les accusations courantes, on y mentionne que les Croates voulaient "un degré croissant de souveraineté » (Le Figaro, 13 décembre 1971), une "confédération yougoslave " (Le Monde, 8 janvier 1972), une "Fédération danubienne " (Le Monde, 27 janvier 1972). Le journaliste Veyrier mentionne même une «totale indépendance» (L'Humanité, 10 janvier 1972) et Bernard Margueritte « l'annexion d'une partie - considérée comme croate - de la Bosnie-Herzégovine » (Le Monde, 7 janvier 1971). Ce dernier fait part également de la théorie selon laquelle l'URSS aurait soutenu le mouvement croate et l'indépendance de la Croatie en échange de bases militaires à Rijeka (Le Monde, 7 janvier 1972).

Enfin, Le Monde fait, à la fin de la période, un bilan humain de cette crise. Yankovitch indique que "selon les statistiques officielles, 255 fonctionnaires du parti croate ont présenté leur démission, 143 ont été révoqués et 357 membres exclus du parti » et que "les rédactions de plusieurs journaux ont été remaniées, certaines publications ont été interdites » (Le Monde, 26 janvier 1972) parmi lesquels on compte L'Hebdomadaire croate de la Matica Hrvatska ${ }^{7}$. Margueritte ajoute que « des centaines de militants du parti ont 
été éliminés à tous les échelons, des journaux estudiantins notamment sont interdits " et que «des dizaines d'étudiants sont emprisonnées» (Le Monde, 7 janvier 1972). Ce n'est que quelques mois plus tard que les principaux protagonistes seront condamnés à des peines de prison (Veselica 7 ans, Đodan 6 ans, Gotovac et Budisa 4 ans, Čičak et Paradžik 3 ans). La liste des personnes arrêtées et condamnées est néanmoins plus longue, tout comme ceux qui ont vu leurs carrières professionnelles freinées ou bloquées ${ }^{8}$. Les dirigeants croates, écartés de la vie politique, n'ont pas été condamnés à des peines de prisons.

Cette chronologie montre une suite d'événements et d'informations élémentaires, souvent sans explications ou interprétations. On remarque aussi que les journalistes ne se sont pas beaucoup étendus sur la répression exercée sur les étudiants et les intellectuels.

Mais cette première analyse des articles peut être complétée par une approche plus pointilleuse et précise sur les thèmes principaux recensés dans les textes.

\section{Comment relater les événements - analyse quantitative}

L'analyse quantitative a été faite à partir d'une matrice composée des catégories suivantes : nom du journal, date de l'article, titre de l'article, nom de l'auteur, type d'article, nombre de signes, lieu d'où est écrit l'article, thèmes de l'article, citations directes des protagonistes, disqualifications idéologiques des protagonistes.

\section{a) Sur les articles en général}

La longueur du texte (nombre de signes) dépend avant tout du type d'article. Ici, nous en avons retenu trois : article informatif (brèves et dépêches d'agences), article analytique (plus complet et plus long que le précédent), reportage et commentaire (écrits par des journalistes ou des invités qui proposent une analyse plus poussée et une interprétation des faits). Les textes des deux dernières catégories sont signés (voir tableau 1).

Tableau 1 : Place du Printemps croate dans les journaux français : typologie et longueur des articles

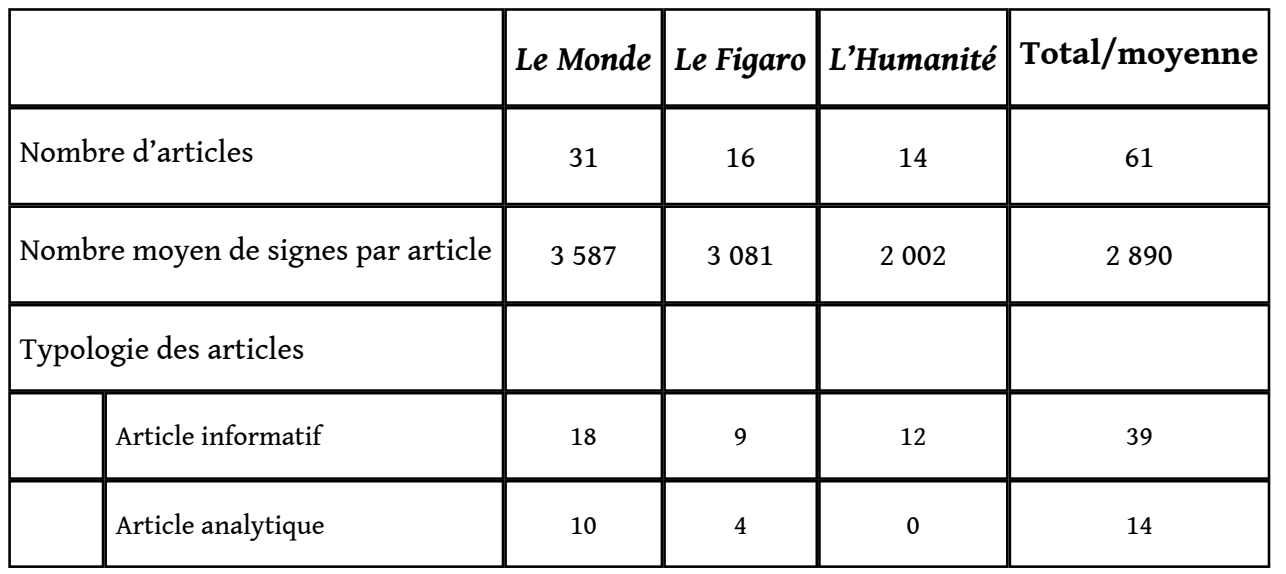




\begin{tabular}{|l|l|l|l|l|l|}
\hline & Reportage et commentaire & 3 & 3 & 2 & 7 \\
\hline
\end{tabular}

Le Monde est le quotidien qui a été le plus prolifique sur les événements croates, non seulement par le nombre d'articles, mais aussi par leur longueur. Le type d'article le plus courant (les deux tiers) est l'article informatif, dont une moitié est issue d'agences de presse (Agence France Press (15), et collaboration des agences AFP, Reuter et United Press International (6)), tandis que l'autre moitié n'est pas signée (18). L'Humanité semble avoir été la moins intéressée par la crise croate touchant pourtant un pays socialiste.

Le dernier tiers des articles est signé par des journalistes ou des invités. Le Monde a le plus grand nombre d'articles analytiques, L'Humanité aucun. Peut-être en raison de l'absence de correspondant sur place, à la différence du Monde avec Paul Yankovitch (10) ou du Figaro avec Mira Traikovitch (4). Etant donné que l'événement a pris des dimensions plus importantes, toutes les rédactions ont engagé des envoyés spéciaux, ou bien demandé à des connaisseurs ou des spécialistes de la Yougoslavie de faire un reportage ou d'écrire un commentaire ou une tribune libre. Bernard Margueritte a ainsi signé deux reportages et Milovan Đilas un " point de vue " pour Le Monde, Sacha Simon a écrit deux " grands reportages » pour Le Figaro, enfin Max Léon et Marcel Veyrier un article chacun dans la rubrique « Points de repères " pour L'Humanité. Tous ces auteurs sont journalistes, à l'exception de Đilas. Si l'orientation politique du quotidien a son importance (Le Monde est plutôt un journal de centre-gauche, Le Figaro de droite, tandis que L'Humanité est l'organe central du Parti communiste français), le ton de l'article dépend aussi du journaliste qui le signe.

On remarque que les articles ont souvent été écrits depuis Belgrade (30 de Belgrade, 10 de Zagreb, 21 non précisés), ce qui signifie que les journalistes n'ont pas été sur place, en l'occurrence à Zagreb, pour y suivre les événements, et qu'ils rapportent nécessairement alors des informations de seconde main. Si les articles informatifs laissent supposer que l'objectivité y occupe une place importante, on peut néanmoins s'interroger sur l'information qui y est véhiculée. Pour cela, il convient de se pencher sur d'autres résultats de l'analyse quantitative.

\section{b) Quels sont les thèmes !}

On a pu identifier dans les 61 articles 28 thèmes (tableau 2) que l'on peut regrouper en quatre catégories : (1) thèmes ayant pour sujet les opinions et les activités des acteurs du Printemps croate (étudiants, membres de la Matica Hrvatska, dirigeants croates démissionnaires) ; (2) thèmes ayant pour sujet les autorités yougoslaves (parmi lesquels les nouveaux dirigeants croates) ; (3) thèmes ayant pour sujet les réactions et les mesures des autorités communistes face au Printemps croate et (4) thèmes ayant pour sujet le nationalisme serbe. Il convient de souligner ici que chaque article peut avoir plusieurs thèmes qui ont tous été pris en compte, qu'il soit question du thème principal ou non.

Tableau 2 : Représentation des quatre catégories de thèmes dans les articles analysés

\begin{tabular}{|l|l|l|}
\hline Thèmes & Fréquence \\
\hline
\end{tabular}


1) Sur les opinions et les activités des acteurs du Printemps croate

\begin{tabular}{|c|c|}
\hline Sur les dirigeants croates & 16 \\
\hline Sur les revendications de nature financière (devises) & 12 \\
\hline Sur le mouvement croate (général) & 10 \\
\hline Sur les revendications de nature politique & 9 \\
\hline Sur la grève des étudiants & 8 \\
\hline Sur la Matica Hrvatska & 8 \\
\hline Sur les protagonistes de l'étranger & 7 \\
\hline Sur les attentats & 7 \\
\hline Sur les intellectuels croates & 3 \\
\hline Autres & 4 \\
\hline Total & 84 \\
\hline & \\
\hline
\end{tabular}

2) Sur les autorités yougoslaves

\begin{tabular}{|l|l|c|}
\hline & Sur les nouveaux dirigeants croates (général) & 8 \\
\hline & Sur le parti communiste (général) & 7 \\
\hline & Sur les ouvriers & 4 \\
\hline & Sur Tito & 3 \\
\hline & Sur l'armée populaire yougoslave & 2 \\
\hline & Total & 24 \\
\hline & & \\
\hline
\end{tabular}

3) Sur les réactions et les mesures des autorités communistes face au Printemps croate

\begin{tabular}{|l|l|c|}
\hline & Sur les démissions des dirigeants croates & 21 \\
\hline & Sur les avertissements donnés aux acteurs du Printemps croate & 16 \\
\hline & Sur les arrestations des étudiants & 12 \\
\hline & Sur la réussite et la satisfaction quant au règlement de la crise & 12 \\
\hline
\end{tabular}




\begin{tabular}{|l|l|c|}
\hline & Sur les purges (général) & 10 \\
\hline & Sur les arrestations des membres de la Matica Hrvatska & 4 \\
\hline & Sur le règlement de la question des devises & 4 \\
\hline & Total & 79 \\
\hline & \multicolumn{2}{|}{} \\
\hline 4) Sur le nationalisme serbe & 9 \\
\hline & Total & \\
\hline
\end{tabular}

29 Les résultats présentés dans le tableau montrent clairement qu'un espace quasiment équivalent est accordé aux acteurs du Printemps croate ( 83 fois) et aux réactions et aux mesures qui en ont découlé ( 79 fois). Il a été moins question du pouvoir communiste (22 fois), et à peine du nationalisme serbe ( 9 fois). Si l'on se penche davantage sur la première catégorie, on remarque que très peu de place a été accordée aux raisons politiques et économiques du Printemps croate, qui sont pourtant à la racine même de la crise. On en a parlé à deux reprises, au début de la grève, puis lors des changements relatifs au système de répartition des devises. En revanche, les journalistes se sont plutôt intéressés aux différents groupes de protagonistes des événements (Matica Hrvatska, dirigeants croates...), et surtout aux faits concrets (grève, arrestations, ...) qui font directement l'actualité.

D'une manière générale, les articles sont avant tout factuels, comme la structure de la typologie le montre d'ailleurs, et concernent donc davantage les événements que leurs raisons et explications. Si les thèmes permettent une analyse détaillée du contenu des articles, il est maintenant important de définir les sources qui véhiculent ces informations, autrement dit de savoir à qui est donné la parole.

\section{c) Qui a la parole !}

Les journalistes se sont basés sur diverses sources lors de la rédaction de leurs articles et ont régulièrement retransmis les opinions ou les faits de différents intervenants. Le recensement des sources a permis d'en identifier 16 que l'on peut répartir en quatre groupes (tableau 3) : 1) les acteurs du Printemps croate (étudiants, membres de la Matica Hrvatska, Eglise, dirigeants croates démissionnaires) ; 2) les autorités yougoslaves (Tito, parti communiste, nouveaux dirigeants croates, syndicats, armée, police, médias d'Etat...) ; 3) les autres (Serbes, sources non dévoilées, média de l'étranger...). 4) Quand la source n'est pas connue ou mentionnée, cela signifie que le journaliste informe juste d'un fait, mais sans mentionner l'intervenant (par exemple « les étudiants ont été arrêtés », et non pas «la police dans son rapport a fait part que des étudiants ont été arrêtés »). L'intérêt de ce type d'analyse permet de montrer à quelles opinions, perspectives et interprétations le journaliste donne place par rapport aux thèmes traités. 
Tableau 3 : Identification des sources sur lesquelles se fondent les articles

\begin{tabular}{|c|c|c|c|c|c|c|}
\hline & & \multicolumn{4}{|c|}{ Catégorie de thèmes } & \multirow[b]{2}{*}{ Total } \\
\hline & & 1 & 2 & 3 & 4 & \\
\hline \multicolumn{7}{|l|}{ Sources } \\
\hline & Non précisé & 41 & 32 & 62 & 19 & 154 \\
\hline & Acteurs du Printemps & & & & & \\
\hline & Etudiants, intellectuels et autres civils & 42 & 21 & 41 & 21 & 125 \\
\hline & Dirigeants croates démissionnaires & 10 & 4 & 9 & 1 & 24 \\
\hline & Total & 52 & 25 & 50 & 22 & 149 \\
\hline & Officiels & & & & & \\
\hline & Autorités yougoslaves & 62 & 28 & 62 & 15 & 167 \\
\hline & Tito & 38 & 31 & 44 & 5 & 118 \\
\hline & Total & 100 & 59 & 106 & 20 & 285 \\
\hline & Divers & & & & & \\
\hline & Intervenants serbes & 3 & 0 & 3 & 3 & 12 \\
\hline & Autres & 3 & 1 & 4 & 1 & 11 \\
\hline & Total & 6 & 1 & 7 & 4 & 23 \\
\hline
\end{tabular}

D'une manière générale, on remarque que les sources d'informations s'opposant au Printemps croate (285 fois) sont deux fois plus représentées que celles qui le supportent. Les journalistes ont rapporté les positions de Tito (118 fois) et des autorités yougoslaves, à savoir le parti (108 fois), les organes de répression comme la police et l'armée (34 fois), les ouvriers ( 18 fois) et les médias d'Etat ( 7 fois). En ce qui concerne les positions des protagonistes et des partisans du Printemps croate, elles se repartissent de la manière suivante : acteurs et sympathisant en général (49 fois), étudiants (41 fois), Matica Hrvatska (28 fois), dirigeants croates démissionnaires (24 fois), Eglise (7 fois).

Par conséquent, les journalistes ont avant tout écrit sur le Printemps croate depuis la perspective des détracteurs du mouvement, transmettant par là même leurs opinions 
et leurs visions des événements et mettant finalement de côté ceux qui se trouvent à son origine même.

Une asymétrie semblable s'observe également pour les citations directes (il peut être question aussi bien d'un mot que d'une phrase entière à condition qu'ils soient mis entre guillemets) (tableau 4). En effet, des 102 citations décomptées, 67 proviennent de personnes, de milieux ou d'institutions qui ne soutiennent pas le Printemps croate. Celles de Tito représentent même un tiers des citations (24), soit trois fois plus que celles des partisans du mouvement croate (21 fois).

Tableau 4 : Nombre de citations selon les intervenants

\begin{tabular}{|c|c|c|}
\hline \multirow[t]{2}{*}{ Source } & & Nombre de citations \\
\hline & \multicolumn{2}{|l|}{ Autorités politiques yougoslaves } \\
\hline & Josip Broz Tito & 24 \\
\hline & Organes répressifs (armée, police) & 12 \\
\hline & Ligue des communistes & 10 \\
\hline & Médias d'Etat & 4 \\
\hline & Milka Planinc & 3 \\
\hline & Vladimir Bakarić & 2 \\
\hline & Communistes de Sisak & 2 \\
\hline & Parlement de la RS de Croatie & 1 \\
\hline & Josip Vrhovec & 1 \\
\hline & Jakov Blažević & 1 \\
\hline & Dušan Dragosavac & 1 \\
\hline & Jure Bilić & 1 \\
\hline & Džemal Bijedić & 1 \\
\hline & Ivo Perišin & 1 \\
\hline & Veljko Vlahović & 1 \\
\hline & Total & 67 \\
\hline & Acteurs du Printemps croate & \\
\hline & Etudiants & 6 \\
\hline
\end{tabular}




\begin{tabular}{|l|l|c|}
\hline & Acteurs anonymes & 4 \\
\hline & Cardinal Franjo Kuharić & 2 \\
\hline & Miko Tripalo & 1 \\
\hline & Matica Hrvatska & 1 \\
\hline & Ivan Zvonimir Čičak & 1 \\
\hline & Ivan Supek & 2 \\
\hline & Dirigeants démissionnaires (anonymes) & 1 \\
\hline & Savka Dabčević Kučar & 15 \\
\hline & Dragutin Haramija & 21 \\
\hline & Total & \\
\hline & & \\
\hline & Autres & 1 \\
\hline
\end{tabular}

Du fait de leur longueur et de la volonté du journaliste de faire une enquête de terrain et donc de discuter avec les principaux protagonistes, les reportages sont particulièrement intéressants en ce qui concerne les citations.

On a vu que les paroles de Tito était assez souvent rapportées dans les journaux. L'Humanité, plus précisément Veyrier, a même cité des extraits de ses discours fait au cours du Présidium de la Ligue des communistes de Yougoslavie le 2 décembre 1971 et d'autres discours dont l'auteur n'a précisé l'origine (L'Humanité, 10 janvier 1972).

En ce qui concerne les étudiants, les citations sont très courtes puisqu'il s'agit surtout de mots clés, à l'instar de "pillage » quand il est question de la répartition des devises. Celui qui a accordé le plus de place aux étudiants est Bernard Margueritte, journaliste au Monde et envoyé spécial à Zagreb en janvier 1972. Il avait alors discuté avec des étudiants, dont il n'a pas livré les noms et de manière très discrète, dans un café bruyant pour déjouer la surveillance de la police (voir Le Monde du 7 janvier 1972 notamment sur les étudiants). Les jeunes lui expliquent alors que l'une des principales raisons de leur grève était Tito : «c'est que nous en avions assez de voir Tito reçu en Occident comme le symbole du socialisme "ouvert". L'autogestion n'est qu'une triste plaisanterie. Quelle démocratie y a-t-il là ! ». À l'égard du nationalisme, les étudiants n'ont pas vraiment une position très claire. D'un coté, ils disent «est-ce être nationaliste que de demander le respect de ses droits!", de l'autre, dans la résolution des étudiants du 22 décembre, ils condamnent avec fermeté «toutes les forces qui veulent présenter l'intelligentsia croate de gauche et spécialement les étudiants de l'université de Croatie comme des nationalistes chauvins et séparatistes ». Par ailleurs, à la différence de Tito qui félicite les ouvriers de ne pas avoir soutenu la grève des étudiants, ces derniers ajoutent : « Dites bien, insistent les étudiants, que tout le monde était derrière nous, les ouvriers aussi ». Ils ont également donné leur témoignage de la 
répression : " plus de six cents d'entre nous ont été arrêtés après la manifestation de la Place de la République ; une trentaine sont encore emprisonnés ». Ces déclarations sont les seules déclarations négatives dans l'ensemble des journaux sur la Yougoslavie, Tito et le parti. Sur les Serbes, il est dit : "les Serbes sont les nouveaux Soviétiques » et "l'armée comme la police sont serbes à $85 \%$ ». On a retrouvé une critique semblable chez Simon qui donne, par ailleurs, la réponse serbe à cette accusation : "Oublie-t-on que ces cadres sont issus de la Résistance qui était serbe à $95 \%$ !» (Le Figaro, 16 décembre 1971). Néanmoins, il y a peu de critique à l'égard des Serbes. Lors du séjour de Margueritte à Zagreb, le mouvement croate est plus ou moins essoufflé. Le journaliste rapporte les paroles des étudiants qui ne regrettent pas d'avoir voulu changer les choses et qui résonnent comme un bilan de leur action : « ce monde prend conscience qu'il y a ici non une quelconque province, mais une nation vieille de trois mille ans qui réclame le respect de ses droits. Personne ne pourra plus l'oublier. Est-ce ci peu! » (Le Monde, 7 janvier 1972).

38 Au cours de son séjour à Zagreb à la mi-décembre, Simon s'est, quant à lui, entretenu avec les intellectuels, à savoir les responsables de la Matica Hrvatska (Jozo Ivičević, Vlado Gotovac, Šime Đodan). Il a fait part de leur mécontentement à l'égard de la politique financière et des conditions politiques en Croatie. De même, Simon est le seul qui a mentionné l'année 1968 quand les intellectuels croates ont essayé de séparer le croate du serbe (il est question ici de la Déclaration sur l'appellation et la position de la langue littéraire croate de 1967). Malheureusement, il n'y a pas d'informations supplémentaires sur ce sujet. En revanche, outre les nombreuses critiques du parti à l'égard de la Matica Hrvatska, les intellectuels en général sont également visés. En effet, ils occupent une place souvent délicate dans les systèmes communistes en raison de la liberté de pensée qui, souvent, les caractérise. Ainsi, Tito a "surtout été sévère pour les intellectuels dans les universités qui "voyagent souvent en Occident" et qui transmettent aux jeunes générations des idéologies contraires au marxisme » (Le Figaro, 23 décembre 1971). Les seuls compliments que Tito a faits étaient destinés aux ouvriers et à l'Armée populaire yougoslave.

39 Le parti a également fait de nombreuses critiques à l'égard des dirigeants croates. Pourtant, Sacha Simon rapporte les opinions positives des Croates sur leurs dirigeants ; il en veut pour preuve que Tripalo était souvent surnommé «le John Kennedy croate » (Le Figaro, 10 janvier 1972). Margueritte fait part d'informations allant dans le même sens (Le Monde, 8 décembre 1972). Il rapporte aussi l'amertume de Tripalo lorsqu'il apprit les changements concernant la répartition des devises en décembre 1971, qui étaient précisément ce qu'il avait proposé avant sa destitution, mais sans succès.

L'Eglise a aussi été présentée comme soutenant plus ou moins ouvertement le mouvement croate (Le Figaro, 16 décembre 1971, Le Monde, 7 janvier 1972). Margueritte rapporte les paroles d'un évêque de Zagreb expliquant que l'Eglise est « restée fidèle à son rôle historique comme ferment et ciment de l'unité nationale croate ». Malgré tout, on ne parle que très peu de l'Eglise et de l'étranger qui regroupe divers " ennemis » de la Yougoslavie, comme les services de renseignements étrangers, l'URSS et l'émigration politique.

41 Les opinions des acteurs et des détracteurs du Printemps croate sont tout à fait marquées et clairement opposées. C'est ainsi qu'elles ont été transmises dans les journaux français, mais de manière asymétrique. Les critiques émises par le parti à l'égard du mouvement croate sont nombreuses, le contraire est beaucoup plus rare. 
Mais il est possible d'aller encore plus loin dans cette analyse. Une analyse des mots clés reflétant le discours peut, à ce titre, être particulièrement instructive.

\section{d) Quels mots utilise-t-on !}

42 Le recensement des disqualifications aussi idéologiques que radicales que les uns ont pu avoir à l'égard des autres est tout à fait représentatif (tableau 5). Pour des raisons pratiques, on a procédé par lemmatisation - c'est-à-dire par l'analyse lexicale d'un texte en regroupant les mots appartenant à une même famille (par exemple, nationalisme regroupe aussi les formes comme nationaliste, nationalistes, etc.).

Tableau 5 : Disqualifications idéologiques des acteurs et détracteurs du Printemps croate

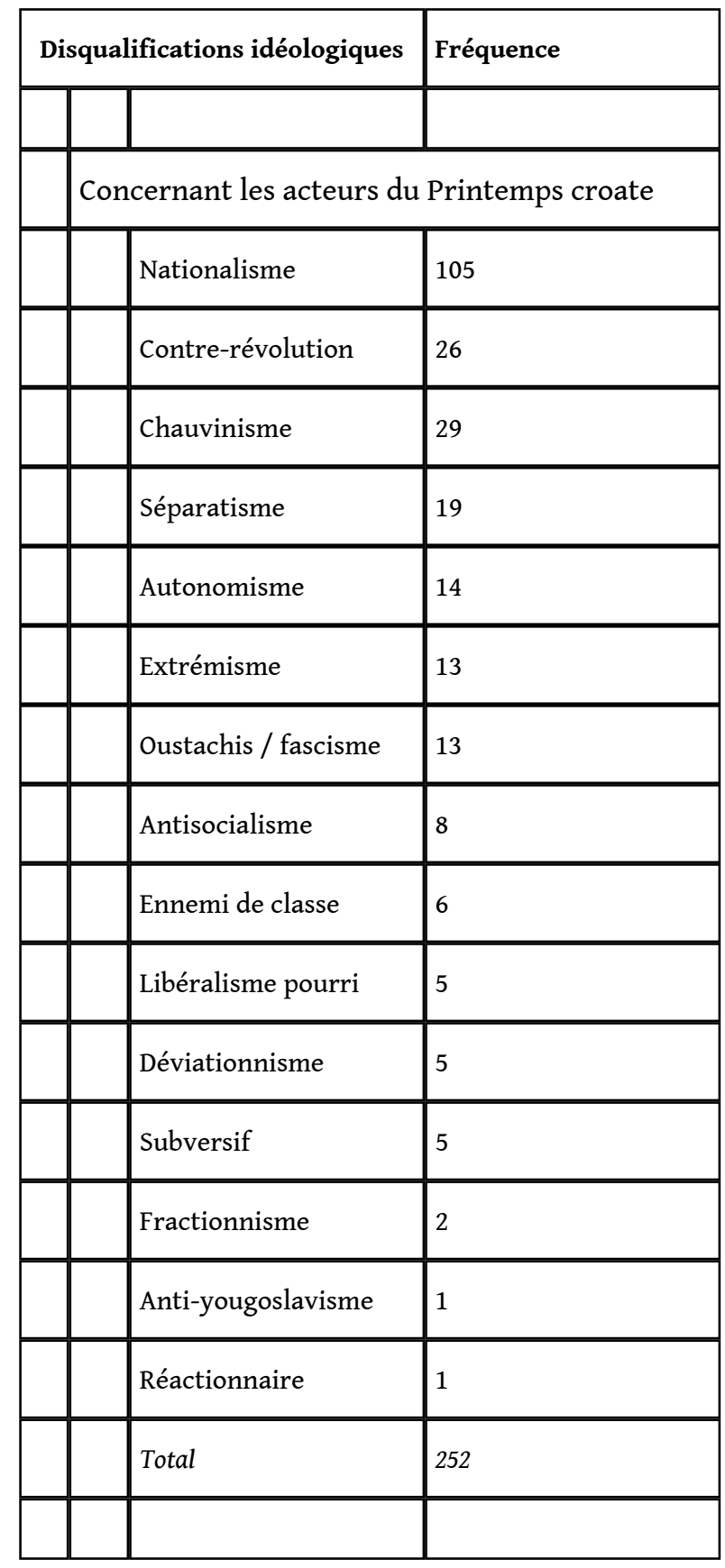




\begin{tabular}{|l|l|l|l|}
\hline & \multicolumn{3}{|l|}{ Concernant les détracteurs du Printemps croate } \\
\hline & & Centralisme & 10 \\
\hline & & Pillage & 6 \\
\hline & & Unitarisme & 4 \\
\hline & & Colonialisme & 4 \\
\hline & & Total & 24 \\
\hline
\end{tabular}

Les disqualifications à l'égard du Printemps croate et de ses partisans sont nombreuses. Elles sont générales (comme extrémisme, nationalisme, oustachi, fascisme) ou encore typiquement idéologiques, à savoir appartenant à la terminologie communiste (comme anticommunisme, contre-révolution, antisocialisme, ennemi de classe...), mettant en danger l'intégrité de la Yougoslavie (séparatisme, autonomisme fractionnisme, antiyougoslavisme). Les disqualifications que les acteurs du mouvement croate ont pu avoir à l'encontre du parti et de la Yougoslavie montrent surtout le rapport problématique entre Belgrade et Zagreb (unitarisme, centralisme, pillage, colonialisme). Il est intéressant de remarquer que les uns et les autres se sont mutuellement accusés de néo-stalinisme. C'est pourquoi ce terme n'a pas été comptabilisé ici.

Si on prend en considération que les sources d'informations contestant le Printemps croate étaient deux fois plus mentionnées (trois fois plus dans le cas des citations) que les sources soutenant ce mouvement, on remarque que le nombre de disqualifications idéologiques exprimées par les premiers est ici sept fois supérieur à celui des seconds. Par conséquent, il apparaît que le discours du parti était non seulement surreprésenté, mais aussi nettement plus idéologique que celui des protagonistes du Printemps croate.

D'une manière générale, les faits et les explications du Printemps croate sont issus avant tout des autorités yougoslaves qui contrôlent non seulement les médias yougoslaves et donc l'information, mais qui peuvent aussi faire l'actualité en faisant des déclarations devenant ainsi l'objet d'article de journaux. Dans les dépêches quotidiennes comme dans les reportages, les journalistes reprennent leur terminologie, discours et positions avec ou sans guillemets. Ceux qui ont fait l'événement et l'actualité, à savoir les étudiants, les intellectuels et même les dirigeants croates, ont finalement rarement eu l'occasion de faire connaître leurs revendications, de les expliquer et donc de les transmettre. Cette carence d'information peut être le résultat d'au moins deux choses. Il existe soit un manque d'intérêt véritable pour le problème de la part des journalistes ou de la rédaction, ce qui aboutit à une certaine superficialité, soit une volonté consciente de ne pas faire état des problèmes en Yougoslavie ou de les minimiser. À ce titre, l'Humanité semble avoir porté peu d'intérêt pour la crise croate puisque ni correspondant ni envoyé spécial n'ont écrit pour le quotidien. Outre les brèves et les dépêches, L'Humanité a publié seulement deux articles engagés, le premier sur la Yougoslavie à l'occasion du 29 novembre, le second sur la crise, mais en citant largement les discours de Tito et condamnant les Croates. S'attarder sur ceux qui ont écrit les articles, à savoir les journalistes, s'impose donc. 


\section{La Yougoslavie et les journalistes}

Les faits ne sont pas nécessairement une information neutre. Ils peuvent être justes, mais néanmoins incomplets, ce qui a évidemment une incidence sur la perception et la compréhension d'un événement. Si les journalistes peuvent plus difficilement exprimer leurs opinions au travers des articles informatifs, c'est moins le cas dans les articles analytiques (malgré tout très informatifs aussi), et surtout dans les reportages et les commentaires. En effet, au-delà du souci d'impartialité, ils y laissent davantage paraître leurs opinions et leurs visions des événements. Néanmoins, peu d'articles soutiennent ouvertement un côté plutôt qu'un autre. On remarque davantage l'expression d'une plus ou moins grande compréhension à l'égard de l'une ou de l'autre partie en conflit (ce penchant peut être léger et pas nécessairement ouvert). Ce qui nous intéresse ici, ce sont précisément ces phrases ou ces expressions qui expriment ou laissent supposer l'opinion ou le penchant du journaliste. Elles sont certes peu nombreuses, mais néanmoins révélatrices. Par ailleurs, les journalistes ont fait des observations plus générales sur la Yougoslavie (comme la Seconde Guerre mondiale) que nous exposerons puisqu'elles dévoilent les opinions de l'auteur, mais sans pour autant en faire une appréciation en raison de l'ampleur de ces sujets.

Les journalistes concernés sont avant tout ceux qui signent leurs articles, à savoir les correspondants, les envoyés spéciaux, les invités. Parmi les auteurs, on en compte trois qui ont apparemment des origines yougoslaves et qui ont donc un rapport particulier à la Yougoslavie. Il est question des correspondants du Monde et du Figaro, respectivement Paul Yankovitch et Mira Traikovich qui utilisent d'ailleurs une version francisée de leur nom de famille, et de Milovan Đilas, célèbre dissident. Les autres journalistes sont des spécialistes du bloc de l'Est et/ou de la Yougoslavie. Marcel Veyrier ${ }^{9}$-envoyé spécial pendant des années en Yougoslavie (avant 1971), auteur d'un livre Tito et la Révolution (1974) - et Max Léon ${ }^{10}$ - envoyé à Moscou - ont écrit pour L'Humanité; Sacha Simon ${ }^{11}$ est d'origine russe, auteur de plusieurs livres sur l'URSS, pour Le Figaro ; Bernard Margueritte ${ }^{12}$, d'origine polonaise, a été correspondant à Vienne (1971-1975) d'où il couvrait l'Europe de l'Est pour Le Monde (auparavant, il était en Pologne, d'où il a été expulsé).

\section{a) Sur le Printemps croate}

48 La majorité des articles de presse laissant transparaitre une opinion et une interprétation de l'auteur tend plutôt à soutenir le parti et à avoir des réticences à l'égard du Printemps croate. Ainsi, Mira Traikovitch, le 14 décembre 1971, a écrit dans Le Figaro un texte qui, tel un épilogue, commente la fin de la crise : «la démission des membres de la célèbre "troïka" croate a mis un terme définitif à une véritable escalade de chauvinisme et de séparatisme qui troublait sérieusement non seulement les sommets du parti yougoslave, mais aussi les plus larges couches populaires, qui y voyaient un danger permanent pour l'unité du pays». Elle ne fait pas mention de répression, mais de "nettoyage " imposé non pas par le sommet du pouvoir, mais demandé par les couches populaires préférant des méthodes "plus énergiques ». Les arrestations sont à peine signalées. De même, elle félicite Tito de ne pas avoir eu recours aux méthodes staliniennes. Fin décembre, Paul Yankovitch, à la suite des changements sur la répartition des devises, considère également que la crise est 
terminée, mais sans faire de commentaire particulier : «la nouvelle direction de cette république fédérée pourra faire valoir qu'en trois semaines à peine elle est parvenue à régler ce qui était devenu le problème numéro un de la république et enlever ainsi à l'opposition son arme principale de combat » (Le Monde, 29 décembre 1971).

En revanche, quelques articles font preuve d'une certaine compréhension envers les revendications croates. C'est le cas d'un article non signé paru en couverture du Monde du 24 décembre 1971 : " non sans raison ses chefs se plaignaient d'être spoliés par l'administration fédérale : privés d'une grande partie des richesses gagnées par le travail des habitants, ils n'avaient pas les moyens matériels d'exercer une "souveraineté" qui leur était reconnue en droit. En exposant sur la place publique leurs revendications, ils traduisaient les sentiments de la plupart de leurs compatriotes". Dans le même article, l'auteur s'interroge sur le bien-fondé des théories soutenant que la crise croate est une conséquence d'un complot fomenté par les puissances étrangères et hostiles à la Yougoslavie : " les dirigeants ont tendance à faire endosser à des forces extérieures la responsabilité des maux qu'ils ne peuvent guérir ». Margueritte de même considère que « les allusions du maréchal Tito aux menaces d'interventions étrangères ne convainquent ni les nouveaux dirigeants croates ni les étudiants ». Il montre aussi une certaine retenue quand à la nomination de Mišković, "homme des temps difficiles", ancien ministre des affaires intérieures de la République socialiste de Macédoine, puis de Yougoslavie, et particulièrement actif dans le limogeage de Ranković. Par ailleurs, son frère est à la tête des services secrets de l'armée (Le Monde, 7 janvier 1972). Face à la crise, les autorités ont engagé un homme qui saura faire face aux événements.

Margueritte ajoute qu'il considère que "cette explosion nationaliste a, ici comme ailleurs, des sources sociales et économiques ». Dans son long commentaire, Đilas pense également que « l'exploitation a, bien entendu, existé » (Le Monde, 30 décembre 1971); Veyrier, au contraire, ne prend pas au sérieux les problèmes économiques. Selon lui, les Croates « spéculaient habilement sur des difficultés économiques réelles, affirmant que la Croatie était sacrifiée par la bureaucratie serbe, que l'Etat fédéral détournait les devises (...) » (L'Humanité, 10 janvier 1972).

51 Margueritte apporte une dimension nouvelle à ce mouvement. Il est d'ailleurs le seul à remarquer qu'à Zagreb, on fait souvent un parallèle entre les événements en Croatie et en Tchécoslovaquie avec, selon lui, "une exagération qui a au moins le mérite de révéler les sentiments de l'opinion ». Il fait également des parallèles avec le mouvement étudiant de Mai 68 en notant que Čičak est « une sorte de Cohn-Bendit croate ». En ce qui concerne les dirigeants croates (qui ont démissionné), il considère qu'ils «se sont depuis longtemps trouvés à la pointe de la lutte pour la démocratisation en Yougoslavie » car Dabčević-Kučar et Pirker n'étaient pas des "apparatchiks », mais appartenaient à l'intelligentsia qui a une certaine liberté de pensée. De plus, ils n'ont cessé de prêcher le calme et de mettre les étudiants en garde contre les " provocateurs ». Margueritte fait également des comparaisons entre le rôle de l'Eglise catholique en Croatie et en Pologne.

52 Les intellectuels et la Matica Hrvatska ont également fait l'objet de quelques commentaires par les journalistes. Margueritte note que l'institution fait beaucoup "pour la propagation de la culture et de la langue croates jusqu'alors négligées ». Au contraire, Veyrier considère que la Matica Hrvatska est « une vieille organisation datant de l'empire austro-hongrois » (L'Humanité, 10 janvier 1972). «Sous prétexte de 
défendre la culture croate, la langue croate que personne ne menaçait plus ", les « contre-révolutionnaires » voulaient, selon lui, « renverser le pouvoir, en finir avec le socialisme, opérer une véritable sécession " et reprenaient "les vieux slogans des Oustachis ». Ce rappel de l'épisode de la Seconde Guerre mondiale ouvre le thème de l'importance de l'histoire yougoslave ainsi que des relations entre les différentes nationalités.

\section{b) Sur l'histoire et la question nationale}

L'histoire intéresse tout particulièrement Max Léon, dont l'article est intitulé : «La Yougoslavie : 28 années d'indépendance et d'édification du socialisme ». Il le publia le 29 novembre 1971, à l'occasion du Jour de la République, jour anniversaire de la proclamation de la Fédération démocratique, « un acte qui marqua la rupture avec un passé d'oppression, de régime royaliste et quasi féodal, de haines raciales et nationalistes, un acte qui ouvrit la voie à un avenir socialiste d'indépendance et de fraternité des peuples». Le présent l'intéresse moins. Il mentionne certes les principaux problèmes du pays, comme l'inégalité des républiques, le rapport entre intérêt local et national, les nationalismes, la démocratie et le centralisme, etc., mais pas la grève des étudiants.

En plus de son actualité, les autres journalistes se sont également penchés sur l'histoire, notamment sur la Seconde Guerre mondiale, fondamentale dans la construction identitaire et politique de la Yougoslavie communiste. Veyrier, Simon et Đilas ont plus particulièrement rappelé l'épisode de la Seconde Guerre mondiale et des relations entre les différentes nationalités. Simon, par exemple, note que les oustachis, «ces fidèles serviteurs des nazis ne représentaient que 2 ou $3 \%$ de la population alors que l'on a eu trop tendance à en faire un synonyme de Croates. L'extermination de 600000 Serbes a d'ailleurs été complétée par celle des intellectuels croates "; Đilas de même parle de « l'extermination des Serbes » et de la réponse des Serbes qui ont utilisé des méthodes semblables; Veyrier indique que « les Oustachis de Pavelic massacrèrent des centaines de milliers de Serbes au nom de ce nationalisme primitif et ultra-révolutionnaire ; et la bourgeoisie serbe, avec le général Mihalovic, [mena des] représailles massives contre les Croates au nom de la Grande Serbie ; le fanatisme religieux sévit dans les deux camps ». Ces thèmes essentiels et récurrents trouvent par conséquent leur place dans les articles.

Une place spéciale est accordée aux relations serbo-croates. Simon parle de «vieilles rancœurs "; Veyrier, de "vieilles querelles »; l'article non signé du Monde, de nations «qui naguère se détestaient » et de l'échec de Tito qui n'a pas réussi à " effacer en un quart de siècle toutes les traces d'une histoire agitée et parfois sanglante ». Simon ne différencie pas les uns des autres, pour lui les Serbes sont des " excités ", les Croates des "extrémistes", le nationalisme des premiers est "plus opérant et centripète ", celui des seconds "irrationnel et centrifuge ». Les journalistes présentent un tableau des relations serbo-croates plutôt belliqueuses.

Plus généralement, la question des relations entre les différents groupes nationaux s'est également posée. Đilas présente les peuples et l'organisation politique de la Yougoslavie suivant la perspective de la problématique des nationalités. Il se penche donc sur la question de l'autonomie des républiques et des régions, il parle de "fraternité et unité», mais sans citer cette expression clé de la Yougoslavie 
communiste. Dans son second reportage, Simon fait une présentation des «minorités nationales ", plus précisément des Roms et des Ruthènes (Le Figaro, 17 décembre 1972). Il écrit en ayant une approche un peu folklorique sur le milieu multiculturel yougoslave. Le titre de son reportage reprend ce thème : "La Yougoslavie aux vingt ethnies" avec comme sous-titre "Six républiques, deux régions autonomes, trois religions, deux alphabets, sept frontières, et pourtant... ». En effet, le sous-titre ajoute : "Sacha Simon souligne les aspects positifs de la Yougoslavie et particulièrement la coexistence harmonieuse de vingt minorités nationales dans les six républiques de la R.F.S.Y » (Le Figaro, 17 décembre 1971) ce qui reflète bien le tableau positif que Simon a dépeint lors de son reportage à Belgrade sur les minorités. Roms et Ruthènes sont satisfaits de leurs statuts.

57 Outre l'aspect multiculturel de la Yougoslavie, cette dernière est aussi intéressante car elle symbolise une troisième voie politique.

\section{c) Spécificités et perspectives de la Yougoslavie}

58 Grâce à la spécificité du socialisme yougoslave, son rôle de leader au sein du mouvement des non-alignés et une position géopolitique qui lui permet d'avoir une relative liberté de manœuvre politique, la Yougoslavie bénéficie souvent d'une réputation particulière. Simon loue son socialisme : «elle aussi utilise la terminologie marxiste, mais l'applique avec tant de tolérance (teintée parfois d'un peu de scepticisme) qu'on est souvent étonné d'être en parfait accord avec des militants du parti dont les propos sont empreints de sagesse et de pondérance » (Le Figaro, 17 décembre 1971). Il souligne que la liberté de parole existe et que d'ailleurs « le régime pénitentiaire, l'un des plus libéraux d'Europe, n'a rien à cacher ».

Par ailleurs, la Yougoslavie occupe une position spécifique en raison de son socialisme moins rigide que celui qui règne dans les pays du Pacte de Varsovie. Elle incarne un socialisme non entaché par les crimes de Staline. Ainsi, pour Veyrier et l'organe central du Parti communiste français, la Yougoslavie est sur le bon chemin. L'Humanité a une opinion positive du titisme et de l'autogestion. Tout comme Mira Traikovitch, elle ne les remet pas en cause. Đilas considère que « la société yougoslave s'est, dans une large mesure, démocratisée, mais les structures politiques demeurent quand même autoritaires ». Et pourtant, malgré les problèmes, « des libertés publiques plus larges et une confédération des Serbes, des Croates, des Slovènes et des Macédoniens ne paraissent donc pas un espoir hors de portée.»

Pourtant, la situation est un peu plus complexe. Simon avait déjà remarqué «le dépérissement de l'Etat » en raison du relâchement du centralisme et donc du contrôle du pays. Dans son second reportage "La Yougoslavie aux vingt ethnies ", au sous-titre "La rébellion croate mise en échec par le centralisme serbe", Simon s'intéresse davantage aux problèmes. L'un d'entre eux est inscrit même dans le sous-titre du texte, à savoir le centralisme serbe qui pose le problème de la répartition du pouvoir au sein du pays. Par ailleurs, le parti est selon lui fragilisé : « une cohésion gravement menacée et qui ne repose que sur l'autorité de Tito». La conclusion de son article est relativement claire et plutôt grave : « en quittant le siège de "M.H.", j'ai pensé au titre amer d'un article de "Jez" le satirique serbe, intitulé "La Yougoslavie sans les Yougoslaves" ». 
61 Margueritte va encore plus loin : «Le pays est entré dans l'après-titisme. Malgré la présence de Tito, la transition est difficile» (Le Monde, 8 janvier 1972). Le journaliste se penche sur le concept même de nationalisme et lui donne une autre perspective. L'un des deux sous-titres de ses articles est « le nationalisme à visage humain ! ( Le Monde, 7 janvier 1972), paraphrase du célèbre « le socialisme à visage humain » du Printemps de Prague de 1968. Ce qui est commun à ces deux concepts est l'idée d'une démocratisation du régime, ce nationalisme « fut et reste un des facteurs de démocratisation du régime, mais on peut se demander si les excès de certains de ses partisans ne mettent pas en danger le pays ». (Le Monde, 7 janvier 1972).

Un mois plus tard, Yankovitch remarque que «le retour à la "légalité socialiste" sur lequel a insisté la conférence annonce un raidissement politique et idéologique du régime ». La phrase suivante ramène à Tito qui «a toutefois affirmé qu'il n'aura pas pour conséquence "un recul de la démocratie" : un retour aux méthodes de répression de l'ancien "Etat centraliste" semble donc exclu. Le régime sait que cette période est révolue " (Le Monde, 29 janvier 1972). La position de Yankovitch prête un peu à confusion puisque il n'est pas clair s'il est question d'une phrase de Tito rapporté au style indirect ou du commentaire de l'auteur.

Les thèmes récurrents comme la Seconde Guerre mondiale, les relations serbo-croates, les nationalismes, la Yougoslavie de Tito, etc., ainsi que les phrases et les expressions révélant les opinions des journalistes sont tout à fait révélatrices. Alors que Léon, dans son article dans L'Humanité, à l'occasion du 29 novembre, fait l'éloge de la Yougoslavie et passe même sous silence la situation en Croatie, Traikovitch du Figaro et Veyrier de L'Humanité expriment leur condamnation du Printemps croate et leur soutien à la Yougoslavie. La crise croate n'a, selon eux, aucunement freiné le développement de la Yougoslavie ni nuit à son développement. Si Simon du Figaro est également laudatif à l'égard du pays, il considère néanmoins que le Printemps croate est le signe d'une crise sérieuse de la Yougoslavie. Alors que Đilas et Yankovitch jugent que cette crise a été finalement surmontée par les autorités yougoslaves, Simon et Margueritte considèrent que les fondements du pays ont été malgré tout quelque peu ébranlés. Margueritte parle même de post-titisme. Evidemment, la chute ou la fin de la Yougoslavie est une possibilité que personne n'a prise en compte.

\section{Conclusion}

64 Même si les journalistes et les agences de presse ont voulu être objectifs et impartiaux et transmettre au mieux l'information concernant le Printemps croate, l'analyse des articles de journaux montre que cela n'est pas véritablement le cas. En effet, les autorités yougoslaves étaient les principales sources d'informations des journalistes, leurs citations étaient surreprésentées en comparaison avec celles des protagonistes du Printemps croate, tout comme les disqualifications qu'ils énonçaient à l'égard de ceuxci. Les explications sont nombreuses. D'abord, le parti ayant le monopole sur la parole et l'information, les acteurs et les principaux protagonistes du Printemps croate n'avaient pas l'opportunité et la possibilité de faire entendre leurs revendications. Il était aussi relativement difficile d'obtenir des informations des acteurs du mouvement croate, notamment après leurs arrestations. Par ailleurs, le rôle des journalistes est également intéressant. En effet, on remarque que les enquêtes de terrain ont finalement été relativement rares (Margueritte pour Le Monde, Simon pour Le Figaro). 
L'Humanité n'en a fait aucune. De plus, certains journalistes - notamment la correspondante du Figaro, Traikovitch - ainsi que la rédaction de L'Humanité ont ouvertement soutenu les autorités yougoslaves et montré leur attachement à la Yougoslavie de Tito. Le Monde apparaît comme le journal le plus sérieux proposant à ses lecteurs le plus grand nombre et le plus large éventail d'articles sur le Printemps croate.

D’une manière générale, les revendications croates sont présentées de manière assez superficielle et brève. L'accent est surtout mis sur la crise qui apparaît comme un incident nationaliste, comme un problème interne à la Yougoslavie et qui a été vite réglé. Les principaux protagonistes croates ont été écartés de la scène publique et la situation a rapidement été régularisée par la répression. Bien que cette crise ait révélé certaines fragilités de la Yougoslavie, soulevées d'ailleurs par certains journalistes (comme Margueritte), d'autres les ont complètement minimisées (comme L'Humanité). Malgré tout, l'existence de ce pays n'a jamais été véritablement remise en cause ni au sein du pays ni à l'étranger. Cette crise ne pouvant avoir d'incidence sur l'équilibre des puissances et la géopolitique mondiale, la une des journaux était plutôt consacrée à la guerre entre le Pakistan et le Bengladesh, qui a apporté l'indépendance au second et changé la donne géopolitique en Asie du Sud. De ce fait, le Printemps croate n'a pas pu obtenir une dimension internationale et susciter l'intérêt des rédactions françaises.

\section{NOTES}

1. «Pregled svjetskog tiska: Pala je maska! Tisak Engleske, Francuske, Švicarske, Njemačke, Italije, Vatikana, Švedske, Španjolske, Sjedinjenih američkih država, Kanade, Australije i N. Zelandije o događajima u Hrvatskoj » [Revue de presse mondiale : le masque est tombé ! Presse d'Angleterre, de France, de Suisse, d'Allemagne, d'Italie, du Vatican, de Suède, d'Espagne, des Etats-Unis et de Nouvelle-Zélande sur les événements en Croatie], Hrvatska Revija, 22 (1), mars 1972.

2. On retrouve cette expression dans Le Monde du 9 août 1972, «Lettre des intellectuels croates » (voir aussi « Pismo hrvatskih intelektualaca », Hrvatska revija, 22 (4), décembre 1972).

3. Cette expression a été utilisée deux fois seulement (Le Monde du 14 décembre 1971 et du 27 janvier 1972).

4. Maticka (Marijan), « Hrvatski prosinački događaji 1971. i svjetska javnost : primjer pariškog "Le Mondea" » [Les événements croates de décembre 1971 et l'opinion internationale : l'exemple du Monde], Časopis za suvremenu povijest, 38 (3), janvier 2007.

5. Il y a de nombreux témoignages comme Dabčević-Kučar (Savka), '71 : hrvatski snovi i stvarnost [1971: les rêves croates et la réalité], vol. I-II, Zagreb: Interpublic, 1997; Tripalo (Miko), Hrvatsko proljeće [Le printemps croate], Zagreb: Globus, 1990 ; Šošić (Hrvoje), Slom hrvatskog komunističkog proljeća 1971 [La débâcle du printemps croate communiste de 1971], Zagreb : Školska knjiga, 1997 ; Kaštela (Slobodan), Novak (Božidar), Veselica (Vladimir), ur, 25. obljetnica boljševičkog udara i sjećanje na Hrvatsko proljeće [Le 25ème anniversaire du coup d'État bolchévique et souvenirs du Printemps croate], Zagreb: HAZU, 1997. Il y a moins d'ouvrages historiographiques; on consultera Bilandžić (Dušan), Hrvatska moderna povijest [Histoire croate 
moderne], Zagreb: Golden Marketing, 1999; Klasić (Hrvoje), Hrvatsko proljeće u Sisku [Le Printemps croate à Sisak], Zagreb: Srednja Europa, 2006; Dukovski (Darko), Istra i Rijeka u Hrvatskome proljeću [L'Istrie et Rijeka dans le Printemps croate], Zagreb : Alineja, 2007.

6. Certains des acteurs du Printemps croate joueront effectivement de nouveau un rôle sur la scène publique et surtout politique dès 1990. Le nom de Franjo Tudjman (HDZ) est bien connu : ce personnage fut le premier président de la République de Croatie; ou encore celui de Dražen Budiša (HSLS), qui s'est notamment présenté aux élections présidentielles de 2000. Parmi les personnalités clés de cette période, on peut aussi mentionner Ivan Zvonimir Čičak et Vlado Gotovac. Le premier s'est surtout investi dans les Droits de l'Homme au sein du Comité Helsinki croate dont il est le président. Le second a également fait une carrière politique (HSLS puis LS), en plus de son travail littéraire, et est notamment connu pour ses talents d'orateur. Il est décédé en 2000.

7. L'hebdomadaire paraît du 16 avril ( $1^{\mathrm{er}}$ numéro) au 10 décembre 1971 ( $34^{\mathrm{e}}$ numéro).

8. Jandrić (Berislav), «Represivne mjere komunističkog režima prema hrvatskoj političkoj oporbi 1945. - 1975. godine : Najznačajniji politički procesi » [Les mesures répressives du régime communiste à l'égard de l'opposition politique croate 1945-1975: les principaux procès politiques], in Fleck (Hans-Georg), Graovac (Igor), ur, Dijalog povjesničara-historičara 9, Zagreb : Friedrich Naumann Stiftung, 2005.

9. « Décès de Marcel Veyrier », L'Humanité, $1^{\text {er }}$ juillet 2002, consulté sur http ://www.humanite.fr/ Deces-de-Marcel-Veyrier le 2 avril 2010.

10. «Décès de Max Leon, journaliste à L'Huma », Libération, 2 avril 2010, consulté sur http :// www.liberation.fr/medias/0109408181-deces-de-max-leon-journaliste-a-l-huma le 2 avril 2010.

11. "Mort de Sacha Simon ancien reporter au Figaro », Le Monde, 22 décembre 1998, consulté sur http ://www.lemonde.fr/web/recherche_breve/1,13-0,37-630623,0.html le 3 avril 2010.

12. Voir son c.v. sur http ://www.stpmo.org/index.php! option=com_content\&task=blogcategory\&id=2\&Itemid=2

\section{RÉSUMÉS}

Les analyses quantitatives et qualitatives des articles du Monde, du Figaro et de L'Humanité sur le Printemps croate de 1971 montrent que les revendications croates exprimées par les étudiants, les dirigeants communistes croates et la Matica Hrvatska n'ont que rarement été rapportées. Les journalistes ont avant tout présenté le point de vue des autorités yougoslaves. On remarque une surreprésentation des disqualifications et des citations des détracteurs du Printemps croate. Les autorités communistes, soutenues d'ailleurs par certains journalistes, ont le monopole sur l'information et les enquêtes de terrain sont rares. Enfin, la crise croate est restée un problème interne à la Yougoslavie.

Quantitative and qualitative analysis of Le Monde, Le Figaro and L'Humanité articles concerning the Croatian Spring (1971) point out that croatian claims expressed by students, croatian communist leaders and the Matica Hrvatska were rarely relayed in the newspapers. Journalists have foremost presented the Yugoslav authorities' point of view. Disqualifications and citations of detractors are overrepresented. Communist authorities, supported by some journalists, monopolize the information and fiel interviews are scarse. Finally, Croatian crisis remained a Yugoslav internal problem. 
INDEX

Index géographique : Croatie, France, Zagreb

Keywords : Croatian Spring, french newspapers, national emancipation

Mots-clés : émancipation nationale, presse française, Printemps croate

\section{AUTEUR}

\section{INES SABOTIČ}

Chargé de recherche - Institut društvenih znanosti Ivo Pilar - Institut des sciences sociales Ivo Pilar

Ines.Sabotic@pilar.hr 